Article

\title{
Seasonal Performance Investigation for Residential Heat Pump System with Different Outdoor Heat Exchanger Designs
}

\author{
Shehryar Ishaque and Man-Hoe Kim *10 \\ School of Mechanical Engineering \& IEDT, Kyungpook National University, Daegu 41566, Korea; \\ shehryarbangash1@gmail.com \\ * Correspondence: kimmh@asme.org; Tel.: +82-53-950-5576; Fax: +82-53-950-6550
}

Received: 1 November 2019; Accepted: 5 December 2019; Published: 10 December 2019

\begin{abstract}
A finned tube heat exchanger is a key component used as a condenser or an evaporator in residential air-conditioning (AC) and heat pump systems. The overall cycle performance of these systems is significantly affected by the heat exchanger's geometric design. This study investigates outdoor heat exchanger designs with varying geometric parameters such as the fin pitch, number of tube rows, and tube length, and their effect on system performance based on seasonal energy efficiency ratio (SEER) and seasonal coefficient of performance (SCOP). Air face velocity profiles for each operating condition along the outdoor heat exchangers are determined using CFD, with subsequent cycle simulations for 10 different operating conditions. Results have been validated with the available experimental data. The number of tube rows, fin pitch, and length of tube have been varied from 2-10, 1.4-2.5 mm, and $800-2800 \mathrm{~mm}$ respectively. The numerical results reveals that SEER increases $3.21 \%$ while SCOP increases $5.32 \%$ up to fourth and fifth tube row respectively and remain unaffected thereafter. Similarly, SEER increases by $3.55 \%$ as the tube length is increased from $800-1800 \mathrm{~mm}$, while it increases only $0.67 \%$ for $1800-2800 \mathrm{~mm}$ and the maximum variation of $4.32 \%$ has been found for SCOP. Moreover, increasing the fin pitch reduces SEER and SCOP (except for fin pitch from 1.4 to $1.8 \mathrm{~mm}$ ). Finally, the performance of the system with four different fin configurations have also been investigated and it has been found that slit fins are more effective.
\end{abstract}

Keywords: heat pump system; finned tube heat exchanger; seasonal energy efficiency ratio (SEER); seasonal coefficient of performance (SCOP)

\section{Introduction}

Recently, demand for air conditioning (AC) and heat pump systems around the world has been gradually increasing due to the high level of industrialization and improvement of living standard. These have led to energy and environmental issues like global warming and climate changes. The energy consumption is expected to be increased by $4-5$ times in the next 50 years [1]. According to International Energy Agency (2013), AC and heat pump systems account for almost 700 million metric tons of $\mathrm{CO}_{2}$ equivalent direct and indirect emissions per year. Therefore, efficient heat pump systems are required in order to minimize greenhouse gas emissions [2].

Most of the heating, ventilation, and air conditioning (HVAC) systems are based on the vapor-compression refrigeration cycle, which comprised of four basic components; a condenser, an expansion device, a compressor, and an evaporator. Finned tube heat exchangers are key components used as condensers and evaporators in these systems. The overall performance of heat pump systems are greatly influenced by the heat exchanger design. These heat exchangers consist of several number of tubes connected in different patterns in order to exchange heat effectively. Extensive research 
has shown that the proper design of fin and tubes is the key factor in enhancing its heat transfer performance. Several other geometric parameters like fin pitch, fin spacing, tube patterns, tube length, tube diameter, and the number of tube rows also affect heat exchanger performance [3]. The effect of different geometric parameters on heat exchanger performance is summarized below.

One of the important parameters is the number of tube rows. Several studies have shown a reduction in heat transfer and pressure drop performance with the increasing number of tube rows while a few others have reported an insignificant effect. Rich et al. [4] studied plate heat exchangers and found that the coils with four depth rows have usually low Colburn $\mathrm{j}$ factors as compared to two depth rows due to standing vortices behind the tubes. Similarly, both the Colburn $\mathrm{j}$ factor and friction $\mathrm{f}$ factor decrease with the increasing number of tube rows for herringbone wavy fin and tube heat exchanger at low Reynolds number with varying fin thickness [5]. The effect remains similar even for finned tube heat exchanger with larger fin pitches [6]. On the other hand, Pongsoi et al. [7] found an insignificant effect of the number of tube rows at high Reynolds numbers $(4000-13,000)$ for crimped spiral finned tube heat exchangers. Similarly, Tang [8] investigated finned tube heat exchangers having larger tube diameters with different fin configurations (plain fins, slit fins and delta wing vortex generators). His results revealed that a number of tube rows greater than six has no significant effect on heat transfer and friction performance. Consequently, Wang et al. [9] investigated three types of slit fins under wet conditions and reported an insignificant effect of the number of tube rows on friction factor for all three types of fins, and heat transfer has been reported unaffected for two types but decreased in third case. In order to study the effect of the number of tube rows on energy consumption, Erdem [10] analyzed the number of tube rows effect on heat pump system performance and energy consumption. He found $12 \%$ and $8 \%$ reduction in energy consumption by increasing the number of tube rows and columns respectively from 2 to 4 . From the existing literature, the effect of the number of tube rows on overall system performance in different operating conditions is not clear. Therefore, in the current study, the effect of the number of tube rows on heat pump system performance in different cooling and heating conditions is investigated.

Another important geometric parameter of the heat exchanger is the fin pitch. The following paragraph summarizes a few studies from literature, showing the effect of fin pitch on heat transfer and pressure drop performance in different heat exchangers. It has been reported by Elmahdy and Briggs [11] and Jang et al. [12] that heat transfer coefficient and pressure drop increase with increasing fin pitch in plate finned tube heat exchangers for laminar flow. Contrary to this, few other studies reported a decrease in heat transfer and friction factor as the fin pitch is increased in wavy [13], plate [4], and spiral L-footed [14] finned tube heat exchangers. Wang [15] studied heat exchanger with slit fins under dry conditions and reported that heat transfer performance reduces as the fin pitch is increased from $1.5 \mathrm{~mm}$ to $2.5 \mathrm{~mm}$. Increasing fin spacing in an annular finned tube heat exchanger also reduces the efficiency of fin [16]. On the other hand, heat transfer and pressure drop performance have been found independent of the fin pitch in plate fins [17] with in-line and staggered arrangement, slit fins [9] under wet conditions, crimped spiral [18] and herringbone wavy [5] fin and tube heat exchangers. The effect remains the same under dehumidifying conditions at a higher number of tube rows and larger fin pitches [6]. A unique trend has been reported by Liu et al. [19] for two number of tube rows in which heat transfer increases with increasing fin pitch initially up to $2.54 \mathrm{~mm}$ and then drops down beyond that point up to $3.15 \mathrm{~mm}$. Onan [20] investigated the effect of fin pitch on COP used in the evaporator of heat pump tumble dryers. An increase of $16 \%$ has been found in COP by decreasing the fin pitch from $5 \mathrm{~mm}$ to $2 \mathrm{~mm}$. To a better understanding of the fin pitch effect in different operating conditions, the current study uses rated as well as partial load operating conditions to study the effect of fin pitch which is not done previously to the best of the author's knowledge.

The length of the tube can also enhance or reduce heat exchanger performance. It should be compatible with the number of tube rows and tube pitch as reported by Ameel et al. [21] and the optimum length is usually selected based on required cooling/heating demand and available space. Ali et al. [22] showed that tube length has a more significant effect on the heat transfer coefficient and 
pressure drop than the shell side. On the tube side, the percent increase in the heat transfer coefficient is more influential than pressure drop whereas, on the shell side, a pressure drop is more significant. It has been reported by Javaherdeh et al. [23] that heat transfer and pressure drop increases as the louver length is increased in louver finned tube heat exchangers due to which more fluid can pass across the fins. They also proposed an optimum louver length to fin height ratio that can further improve the performance.

Besides the number of tube rows, fin pitch, and length of the tube, fin configuration also plays a key role in finned tube heat exchangers performance. Fins are responsible for increasing the heat exchange surface area and reduce boundary layer thickness. The smaller the boundary layer thickness, the smaller will be airside thermal resistance. Some of the commonly used fins are plate, wavy, louvered, and slit fins. As compared to plain fins, wavy fins reduce recirculation zones on airside which increases heat transfer performance and reduces pressure drop [24]. Wen and Ho [25] investigated plate, wavy and compounded fins. Their results showed that wavy fins have better heat transfer and pressure drop performance as compared to flat fins whereas, compound fins (T shaped fins and saw type) can even improve the performance further. Chen et al. [26] studied the behavior of H-type fins in a heat exchanger. It has been reported that the efficiency of H-type fins decreases with increasing fin height or fin width. It has been reported by Santosa et al. [27] that slit fins can enhance heat exchanger performance up to $8 \%$ by minimizing heat conduction and maximizing heat convection across the fluid. Micheli et al. [28] preferred pin fins over plate fins for better heat transfer performance due to the availability of larger volume. The previous research on fin configurations mainly focuses on analyzing specific fin geometry under rated load condition, while the seasonal effect of fin geometry is seldom paid close attention.

Various studies are available in literature that analyze different geometric parameters of heat exchanger under rated load condition. However, these studies are limited to specific geometric designs and peak loads, which only occur $1-2.5 \%$ of a year. To the best of the author's knowledge, no previous study has reported the effect of outdoor heat exchanger geometric parameters on heat pump system performance under partial load operating conditions. Moreover, because of complex and expensive experimental setup required to obtain outdoor heat exchanger geometrical parameters effect on heat pump system performance in different seasonal conditions, most investigations to-date have been based on heat exchangers performance only. Although these investigations have led to useful results, they did not take into consideration the partial load operating conditions effect which keeps on changing throughout the year. Therefore, the current study focuses on heat pump performance based on SEER and SCOP rather than single peak loads. This paper numerically investigated the effect of the number of tube rows, fin pitch, tube length and fin configuration in different cooling and heating conditions. Numerical investigation also allows us to expand the range of varying parameters. The results in this paper should be of use to researchers who are designing an outdoor heat exchanger for a heat pump system based on SEER and SCOP rather than a single peak load design point. This will reduce a huge amount of energy consumption with subsequent reduction in $\mathrm{CO}_{2}$ emissions.

\section{Design Specifications}

\subsection{Physical Description}

Figure 1 shows the heat pump system considered in this study comprised of four main components; outdoor unit, an expansion valve, four indoor units, and a compressor. Finned tube heat exchangers are used as indoor and outdoor units with refrigerant R410A used as a heat transfer fluid inside the tubes circulating throughout the closed cycle. These heat exchangers consist of a large number of tubes that can be arranged in different ways. The outdoor unit heat exchanger considered in the current study consists of three depth rows with a tube diameter of $7 \mathrm{~mm}$. Each row has 60 tubes with louver wide fins. Fan is installed at the top of a heat exchanger and is exposed to environmental conditions. Temperature and airflow distribution varies with seasonal outdoor condition. Four indoor 
unit heat exchangers of equal capacity and same geometric specifications were used which consists of three depth rows with 28 tubes in each row. The refrigerant flow paths for outdoor and indoor units are shown in Figure 2. Detailed geometric specifications for both heat exchangers are given in Table 1. Scroll compressor $(\Phi=7.0 \mathrm{~mm}, \mathrm{H}=2 \mathrm{~m})$ was used in this study with capillary tube $(\Phi=4.76$, $\mathrm{L}=240 \mathrm{~mm}$ ) as an expansion device.

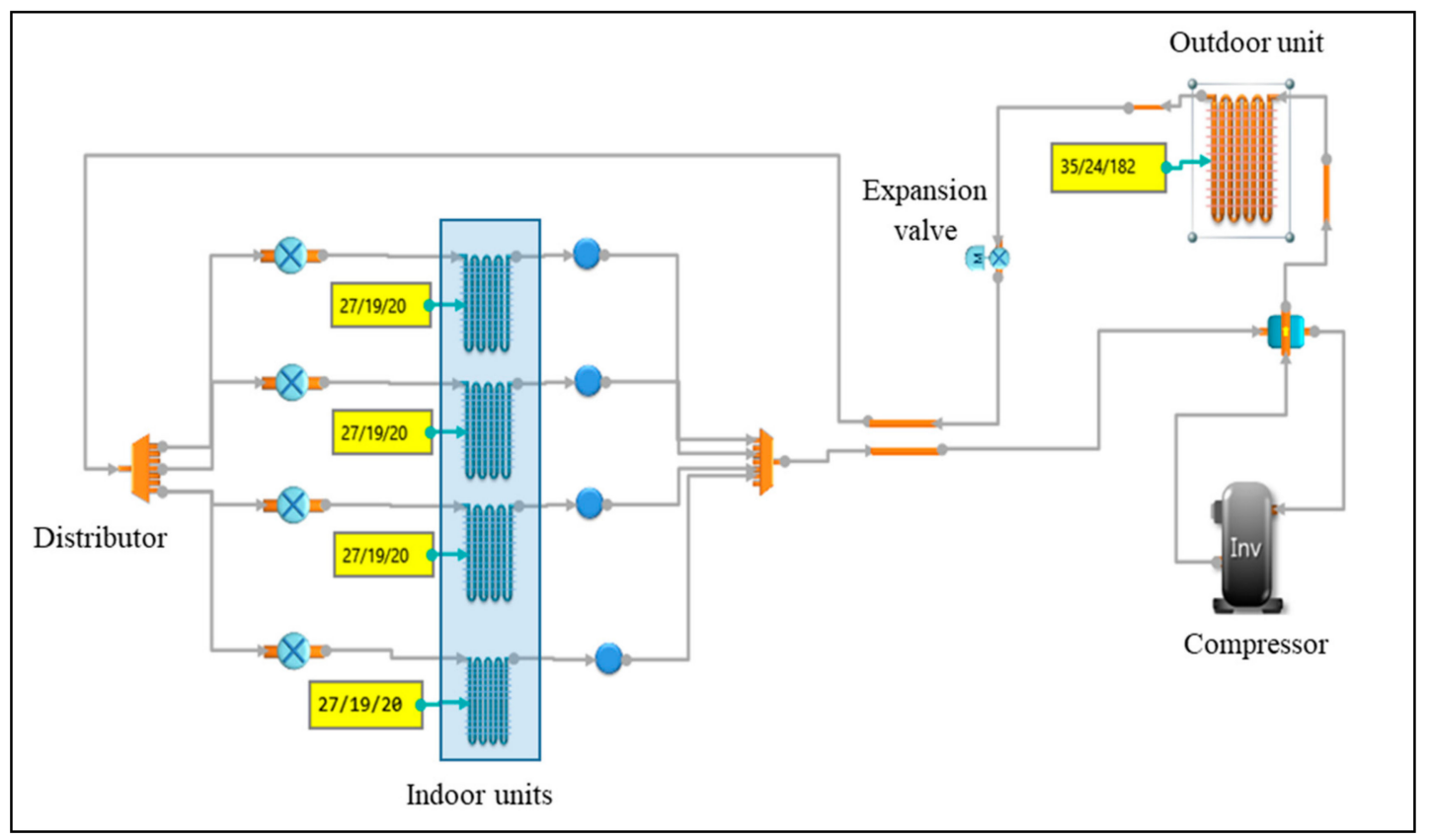

Figure 1. Schematic of the heat pump system.

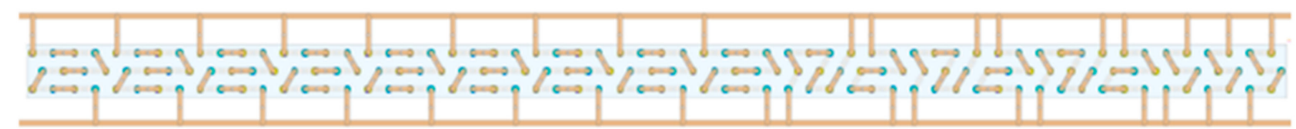

(a) Outdoor unit (60 tubes, 3 rows)

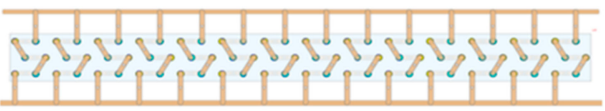

(b) Indoor unit (28 tubes, 3 rows)

Figure 2. Refrigerant path of outdoor and indoor unit heat exchangers.

Table 1. Geometric details of indoor and outdoor unit heat exchangers.

\begin{tabular}{lll}
\hline \multicolumn{1}{c}{ Items } & \multicolumn{1}{c}{ Indoor Unit } & \multicolumn{1}{c}{ Outdoor Unit } \\
\hline No. of tube rows & 3 & 3 \\
No. of tubes per row & 28 & 60 \\
Tube length & $1040 \mathrm{~mm}$ & $1720 \mathrm{~mm}$ \\
Tube inner diameter & $6.3 \mathrm{~mm}$ & $6.3 \mathrm{~mm}$ \\
Tube outer diameter & $7 \mathrm{~mm}$ & $7 \mathrm{~mm}$ \\
Fin pitch & $1.5 \mathrm{~mm}$ & $1.7 \mathrm{~mm}$ \\
Fin thickness & $0.092 \mathrm{~mm}$ & $0.092 \mathrm{~mm}$ \\
Fin type & $\Phi 7$ Slit wide & $\Phi 7$ Louver wide \\
Airflow & Uniform & Non-uniform \\
\hline
\end{tabular}




\subsection{Operating Conditions}

Heat pump and air conditioning systems operate in different outdoor seasonal conditions. These equipment are used in winter as well as summer for heating and cooling purposes. The seasonal variation in the outdoor condition occurs throughout the year. There are eight different cooling and heating conditions according to the European standard EN14825 as shown in Table 2. During summer the outdoor dry and wet bulb temperatures for different cases are $35 / 24,30 / 26,25 / 22$, and $20 / 18^{\circ} \mathrm{C}$ with comfortable indoor temperatures of $27 / 19^{\circ} \mathrm{C}$. Similarly, during winter the dry and wet bulb temperatures are $-7 /-8,2 / 1,7 / 6$, and $12 / 11{ }^{\circ} \mathrm{C}$ with comfortable indoor temperatures of $25 / 15^{\circ} \mathrm{C}$. The outdoor air volume flow rates for the respective cases are 182, 135, 112, and $65 \mathrm{~m}^{3} / \mathrm{min}$ for cooling and $149,135,86$, and $65 \mathrm{~m}^{3} / \mathrm{min}$ for heating. Refrigerant R410A was used as a working fluid charging amount of $12 \mathrm{~kg}$.

Table 2. Seasonal outdoor cooling/heating conditions.

\begin{tabular}{cccccc}
\hline Case & $\begin{array}{c}\text { Air Flow Rate } \\
\left(\mathbf{m}^{\mathbf{3}} \mathbf{/ m i n}\right)\end{array}$ & $\begin{array}{c}\text { Average Face } \\
\text { Velocity }(\mathbf{m} / \mathbf{s})\end{array}$ & $\begin{array}{c}\text { Refrigerant Flow } \\
\text { Rate }(\mathbf{k g} / \mathbf{h})\end{array}$ & $\begin{array}{c}\text { Outdoor } \\
\text { DBT }\left({ }^{\circ} \mathbf{C}\right)\end{array}$ & $\begin{array}{c}\text { Outdoor } \\
\text { WBT }\left({ }^{\circ} \mathbf{C}\right)\end{array}$ \\
\hline EER(A) & 182 & 1.6 & 470 & 35 & 24 \\
EER(B) & 135 & 1 & 323 & 30 & 26 \\
EER(C) & 112 & 0.9 & 209 & 25 & 22 \\
EER(D) & 65 & 0.5 & 112 & 20 & -8 \\
COP(A) & 149 & 1.1 & 245 & 2 & 7 \\
COP(B) & 135 & 1.0 & 159 & 7 & 6 \\
COP(C) & 86 & 0.7 & 95 & 12 & 11 \\
COP(D) & 65 & 0.5 & 65 & & -8 \\
\hline
\end{tabular}

\subsection{CFD Model}

In large outdoor units, the fan is usually installed on the top of a heat exchanger. Airflow velocity at the upper stream rows of a heat exchanger is higher in such cases as compared to downstream rows due to which the performance deteriorates at the lower part of the heat exchanger. In this study, the non-uniform airflow velocity distribution over the outdoor unit heat exchanger is calculated through a commercial CFD code, ANSYS fluent [29]. The outdoor unit consists of 180 total tubes arranged in three depth rows, each row having 60 tubes with louver wide fins arranged in a staggered manner. In order to compute flow across each fin, boundary layer formulation is of high concern. In such cases, SST k-omega models are more accurate that solve the entire flow regime [30] but are computationally expensive and time-consuming. In the current study, fins are not solved actually instead, the heat exchanger has been modeled as a porous medium which is numerically an efficient way to study the performance. A porous medium approach reduces simulation complexities and time requirements without compromising on the accuracy of the results. It can be used for single-phase and multiphase problems, including flow through packed beds, filter papers, perforated plates, flow distributors, and tube banks [29]. A 1D simplification of the porous media model, termed as "porous jump", has been used to model a thin membrane with known velocity/pressure-drop characteristics as adopted by An and Kim [31]. The porous jump model is applied to a face zone and is more robust and yields better convergence. The standard $k-\varepsilon$ turbulence model has been utilized for resolving the turbulence in fluid domain which is the simplest two-equation model. This model allows the turbulent velocity and length scales to be independently determined by solving two separate transport equations. The mesh model is shown in Figure 3. Grid independency study has been performed using six sets of meshes ( 0.48 million, 0.68 million, 0.8 million, 1.0 million, 1.3 million, and 1.5 million). Results shown in Figure 4 identifies the difference between average face velocity values for meshes of 0.68 and 0.8 million, which is less than $1 \%$. Thus based upon considerable less computational time, meshes of 0.68 million have been selected for all operating conditions. 


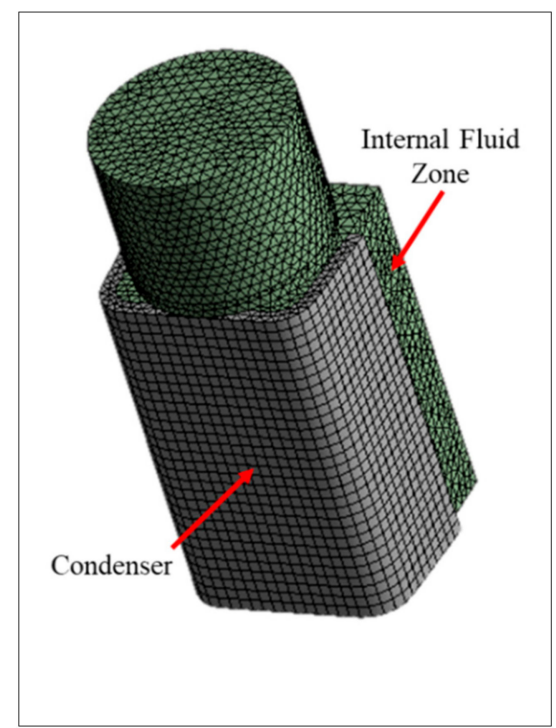

Figure 3. Mesh model of discretized porous medium and fluid flow zone.

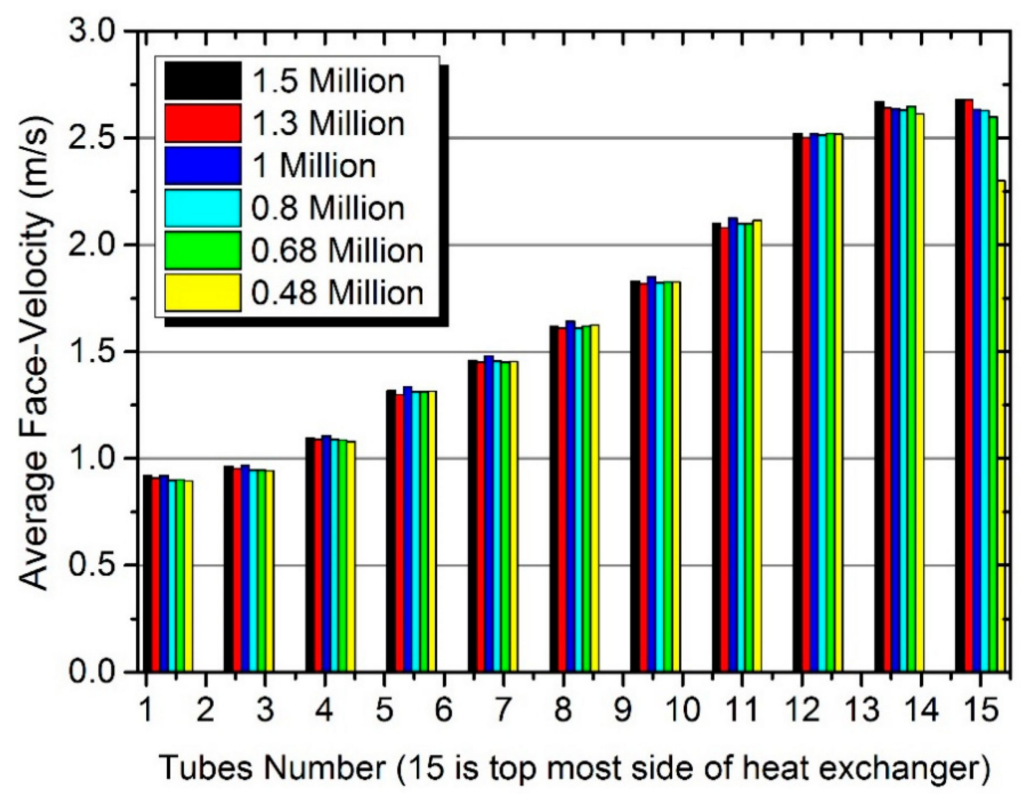

Figure 4. Grid independency study.

Airflow velocity contour for the base case i.e., EER(A) is shown in Figure 5a, which shows maximum velocity at the upper part of the heat exchanger with a gradual decrease towards the base. A sudden decrease to zero at the bottom of the heat exchanger is ascribed due to the heat exchanger ceiling. Numerical results for the base case i.e., EER(A) are compared with experimental data [32] as shown in Figure 5b. All the geometric parameters and flow conditions were kept the same with only the assumption of simplified inner geometry. The CFD results are in good agreement with the maximum percentage difference of $8.75 \%$ on average face velocity value. Slightly over predicted numerical values are due to the assumption of simplified geometry. 


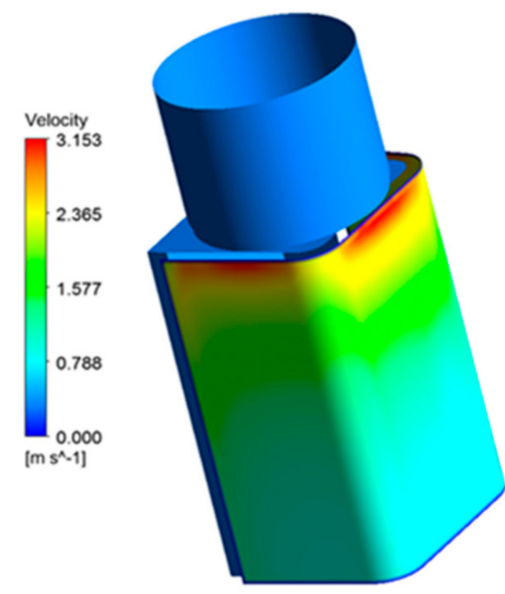

(a)

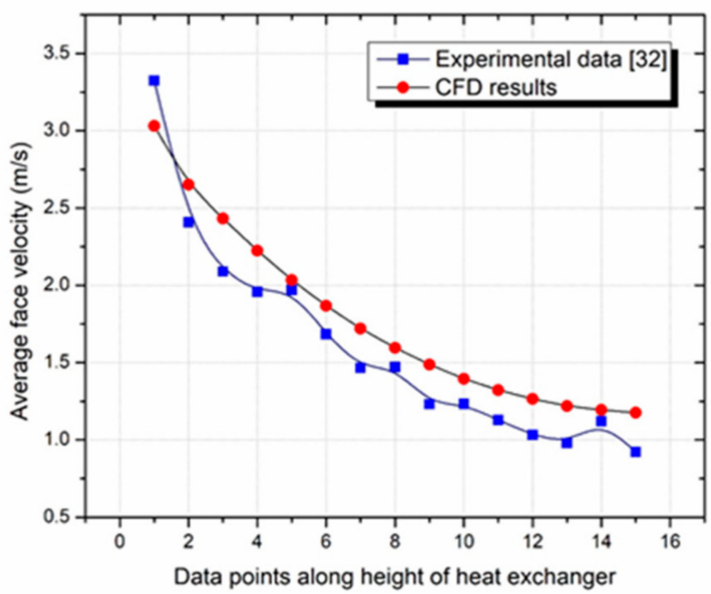

(b)

Figure 5. Airflow velocity (a) contour, (b) distribution along the heat exchanger.

\subsection{Numerical Methodology}

In this study, the heat pump cycle is numerically solved through the cycle simulation program [33] to analyze the effect of outdoor unit heat exchanger parameters on heat pump system performance. The current software has the advantage of solving heat pump systems in both cooling and heating modes and broaden the parametric range. The basic vapor compression cycle is implemented in the software to calculate EER/COP. It includes indoor and outdoor unit finned tube heat exchanger models which act as a condenser or evaporator. These heat exchangers are solved through the tube-by-tube method [34] using non-uniform airflow velocity distribution as an input along with other parameters given in Table 1. Figure 6 summarizes the simulation flow chart to help clarify the numerical methodology.

Air and refrigerant side heat transfer coefficients are calculated using an appropriate heat transfer and pressure drop correlations for either side. Louver fins have been used in the base case for which the Colburn $j$ factor and friction $f$ factor on airside can be calculated from literature [35] as given in Equations (1) and (2).

$$
f=\frac{2 A_{\min } \Delta P}{\rho A_{i} u_{\max }{ }^{2}}
$$

where $A_{\min }$ is the minimum flow area, $A_{i}$ is the surface area exposed to air, $\Delta P$ is the pressure drop, $\rho$ is the air density, and $u_{\max }$ is the maximum velocity.

$$
j=\frac{\eta_{s} h_{c o} \operatorname{Pr}^{2 / 3}}{\rho u_{\max } C_{p_{a}}}
$$

where $\eta_{s}$ is the surface efficiency, $h_{c o}$ is convection heat transfer coefficient at the exterior surface, $\operatorname{Pr}$ is the Prandtl number, $C_{p_{a}}$ is the specific heat capacity of airside. 


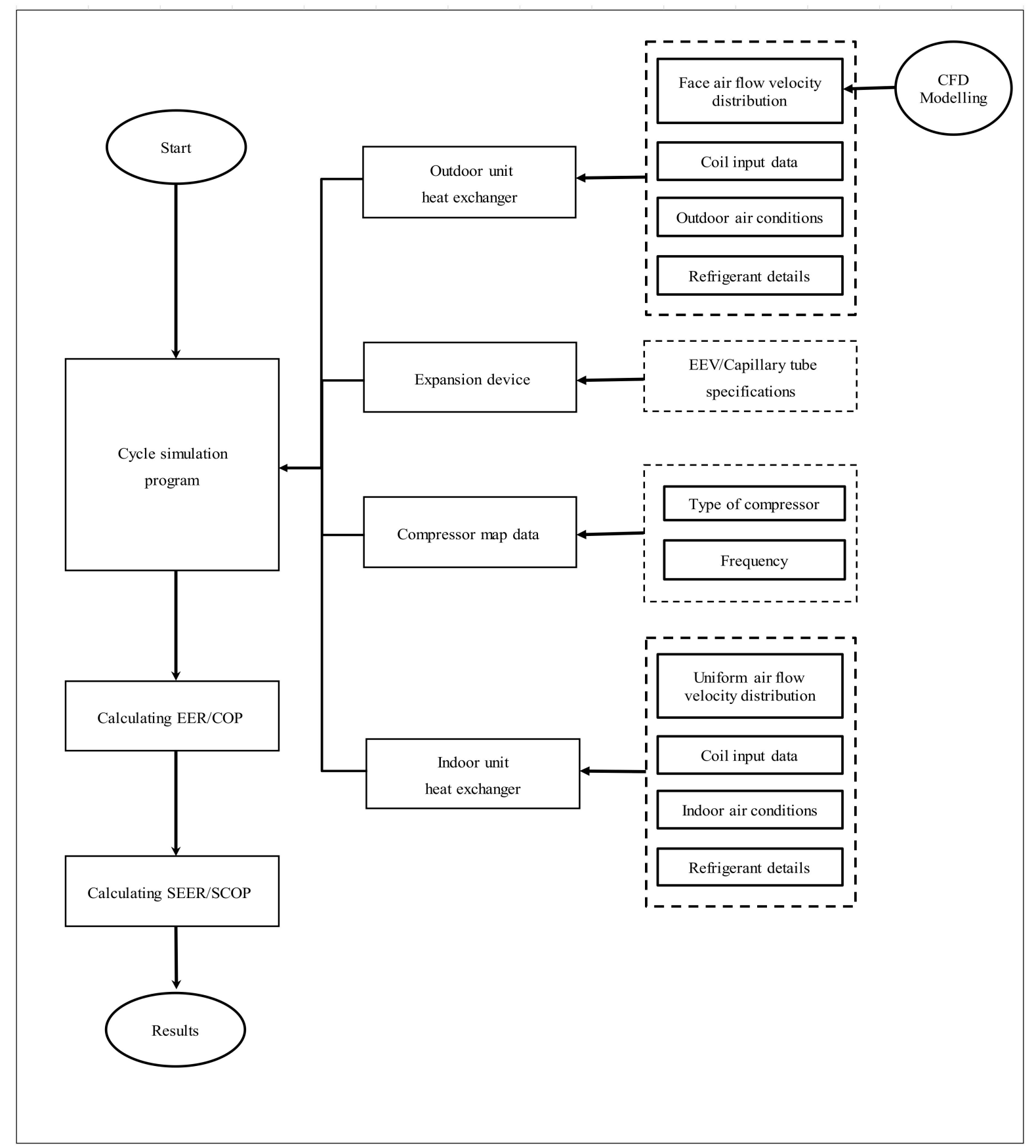

Figure 6. Flow chart of the simulation model.

Refrigerant side heat transfer and pressure drop correlations are based on flow quality i.e., annular flow $(0<x \leq 0.8)$, dispersed flow $(0.8<x \leq 1)$ or superheated flow $(x>1)$. Overall heat transfer coefficient can be calculated using Equation (3).

$$
1 / U_{a n}=R_{t}=R_{i}+R_{t}+R_{o}+R_{f}=\sum R
$$


where $U_{a n}$ is the overall heat transfer coefficient, $R_{t}$ is the total thermal resistance, $R_{i}$ is the inside tube resistance, $R_{t}$ is the tube thermal contact resistance, $R_{o}$ is the outside tube resistance, and $R_{f}$ is the fin to tube contact resistance. These variables are defined as

$$
R_{i}=\frac{A_{i}}{A_{i \_h t} h_{a n}}, R_{t}=\frac{A_{i} t}{A_{p m} k_{t}}, R_{o}=\frac{A_{i}}{A_{o_{-} h t} h_{c o}}, R_{f}=\frac{1}{h_{t}\left(1-\frac{A_{f s}}{A_{i}}\right)(1-\phi)}
$$

where $A_{f s}$ is fin surface area, $A_{i \_h t}$ is tube inside surface area, $A_{p m}$ is mean surface area, $A_{o \_h t}$ is tube outside surface area, $h_{a n}$ is inside tube heat transfer coefficient, $h_{t}$ thermal conductance of the pipe-to-fin contact, $t$ is tube thickness, $k_{t}$ is tube thermal conductivity, $\phi=\frac{T_{f m}-T_{a}}{T_{f b}-T_{a}}$; is the fin efficiency, $T_{a}$ is the air temperature, $T_{f m}$ is the fin mean temperature, and $T_{f b}$ is the fin base temperature. Once the overall heat transfer coefficient has been calculated then air and refrigerant side heat transfer ' $Q_{a}$ ' and ' $Q_{r}$ ' can be evaluated using Equations (4) and (5) respectively.

$$
\begin{gathered}
Q_{a}=\dot{m}_{a} C_{p_{a}}\left(D B T-T_{r i}\right)\left(1-\exp \left(-\frac{U_{a n} A_{i}}{\dot{m}_{a} C_{p_{a}}}\right)\right) \\
Q_{r}=\dot{m}_{r}\left(i_{r a}-i_{r i}\right)
\end{gathered}
$$

where $\dot{m}_{a}$ and $\dot{m}_{r}$ are the air and refrigerant mass flow rates, DBT is the air dry-bulb temperature, $T_{r i}$ is the refrigerant inlet temperature, $i_{r a}$ and $i_{r i}$ are the air and refrigerant side inlet enthalpies respectively. Based on heat transfer, outlet parameters are evaluated, with subsequent pressure drop calculations across each circuit. The total mass flow rate is distributed among circuits in such a way that pressure drop across each circuit remains the same. Pressure drop correlations for two-phase and superheated flows are used according to the refrigerant quality as given in Equations (6) and (7).

$$
\begin{gathered}
\Delta P=\frac{f L}{D_{i}}+\frac{\Delta x}{x_{i n}} \times G_{r}^{2} \times v_{m} \\
\Delta P=\frac{2 f G_{r}^{2} L}{D_{i} \rho}+G_{r}^{2}\left(v_{r o}-v_{r i}\right)
\end{gathered}
$$

where $L$ is the tube length, $D_{i}$ is the inside tube diameter, $\Delta x$ is the quality change, $x_{i n}$ is the inlet quality, $\rho$ is the refrigerant density, $G_{r}$ is the mass flux, $v_{r i}, v_{r o}$ and $v_{m}$ are the inlet, outlet and mean specific volumes respectively. The refrigerant mass fraction across each circuit is given by Equation (8).

$$
\begin{aligned}
F_{i}=\frac{m_{i}}{m_{\text {tot }}} & =\frac{1}{\sum_{j=f i r s t}^{\text {last }}\left(R_{i} / R_{j}\right)^{0.571}} \\
R_{i} & =\Delta P_{i} / \Delta G_{i}^{1.75} \\
R_{j} & =\Delta P_{j} / \Delta G_{j}^{1.75}
\end{aligned}
$$

where $R_{i}$ is the flow resistance through $i$ th circuit through which the flow is flowing as given by Equation (9), $R_{j}$ is the total flow resistance for all the circuits originating from that circuit given by Equation (10) and $F_{i}$ is the fraction of total refrigerant mass flowing through respective circuit.

Once heat exchangers are solved, the outlet refrigerant saturation temperatures of the condenser and evaporator are used as input to solve the heat pump cycle. The software uses built-in compressor map data for the selected type of compressor which adjusted the refrigerant flow rate and compressor power. Isentropic efficiency and volume flow rate of the compressor are calculated at the specified saturation temperatures at the inlet and outlet of the compressor. Refrigerant mass flow rate and compressor power are calculated using thermodynamic properties for the specific refrigerant. EER or 
COP of the heat pump system is calculated by taking the ratio of indoor unit capacity to the compressor input power as given by Equation (11).

$$
E E R / C O P=\frac{\text { Cooling/Heating_Capacity }(k W)}{\text { Power_input }(k W)}
$$

In order to find the average seasonal performance throughout the year, SEER and SCOP are determined analytically using Equations (12) to (17), according to the standard EN14825.

$$
S E E R=\frac{Q_{c}}{\frac{Q_{c}}{S E E R_{o n}}+H_{T O} \times P_{T O}+H_{S B} \times P_{S B}+H_{C K} \times P_{C K}+H_{O F F} \times P_{O F F}}
$$

where $H$ is the number of hours in a year the heat pump is in stated operating mode (thermostat off mode, standby mode, crankcase heater mode, and off mode) and $P$ is the energy consumption of the heat pump in corresponding mode. $Q_{c}$ is defined as the reference annual cooling demand $(\mathrm{kWh})$ and is expressed as Equation (13).

$$
Q_{c}=P_{\text {design-c }} \times H_{c e}
$$

where $P_{\text {design-c }}$ is the energy consumption in design operating mode, and $H_{c e}$ is the number of annual operating hours. By accumulating cooling demand and electricity consumption for each temperature, $S E E R_{\text {on }}$ it can be calculated as the accumulated electricity consumption divided by the accumulated cooling demand as given by Equation (16). The reference annual $S E E R_{o n}$ is given by Equation (14).

$$
S E E R_{o n}=\frac{\sum_{j=1}^{n} h_{j} \cdot P c\left(T_{j}\right)}{\sum_{j=1}^{n} h_{j} \cdot\left(\frac{P c\left(T_{j}\right)}{E E R_{P L}\left(T_{j}\right)}\right)}
$$

where $T_{j}$ is the bin temperature, $P c\left(T_{j}\right)$ is the cooling demand of the building, $h_{j}$ is the number of bin hours occurring and $\operatorname{EER}_{P L}\left(T_{j}\right)$ is the EER values of the unit for the corresponding temperature $T_{j}$ respectively, $\mathrm{j}$ is the bin number, and $\mathrm{n}$ is the number of bins.

Similarly, for average heating seasonal performance SCOP is calculated using a similar procedure, given by Equations (15)-(17).

$$
\begin{gathered}
S C O P=\frac{Q_{h}}{\frac{Q_{h}}{S C O P_{o n}}+H_{T O} \times P_{T O}+H_{S B} \times P_{S B}+H_{C K} \times P_{C K}+H_{O F F} \times P_{O F F}} \\
Q_{h}=P_{\text {design }-h} \times H_{h e} \\
S C O P_{\text {on }}=\frac{\sum_{j=1}^{n} h_{j} \cdot P h\left(T_{j}\right)}{\sum_{j=1}^{n} h_{j} \cdot\left(\frac{\operatorname{Ph}\left(T_{j}\right)-e l b u\left(T_{j}\right)}{\operatorname{COP}_{P L}\left(T_{j}\right)}+e l b u\left(T_{j}\right)\right)}
\end{gathered}
$$

where $P h\left(T_{j}\right)$ is the heating demand of the building, $C_{P L}\left(T_{j}\right)$ is the COP values of the unit, and $e l b u\left(T_{j}\right)$ is the required capacity of an electric backup heater for the corresponding temperature $T_{j}$ respectively.

\section{Model Validation}

Simulation results for cooling and heating capacities have been validated with the available experimental data [32]. The maximum percentage difference found is $8.57 \%$ for cooling capacity and $1.34 \%$ for heating capacity as shown in Figures 7a and 8a respectively. Consequently, EER and 
$\mathrm{COP}$ of the cycle performance have been validated for each condition as shown in Figures $7 \mathrm{~b}$ and $8 \mathrm{~b}$. The maximum percentage difference observed is $2.23 \%$ for EER and $1.97 \%$ for COP.

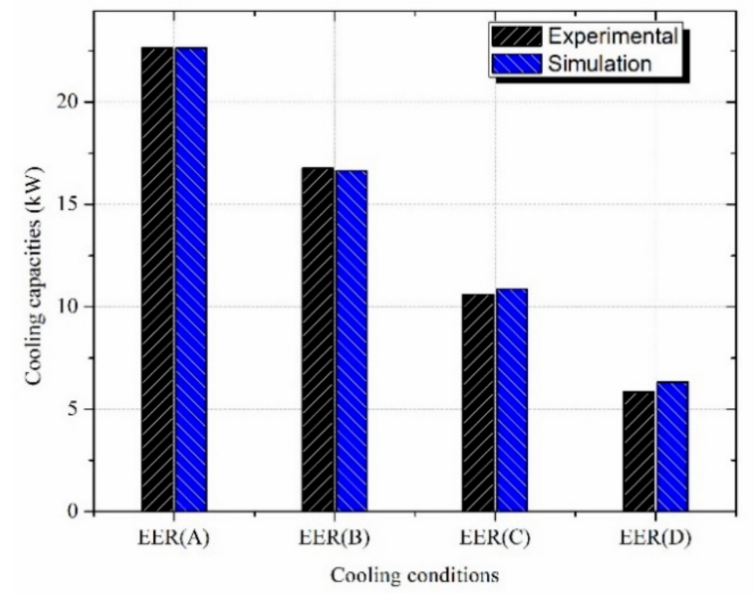

(a)

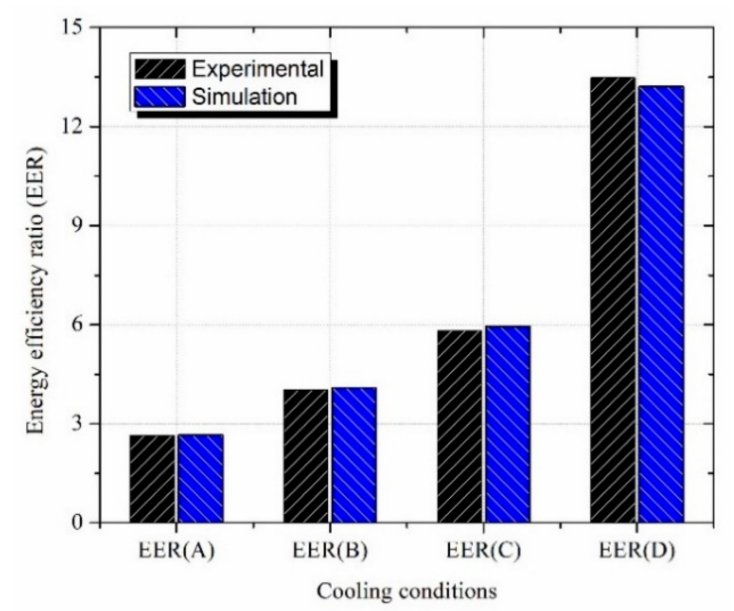

(b)

Figure 7. (a) Comparing cooling capacities of heat exchanger; (b) Energy efficiency ratio (EER) of the cycle.

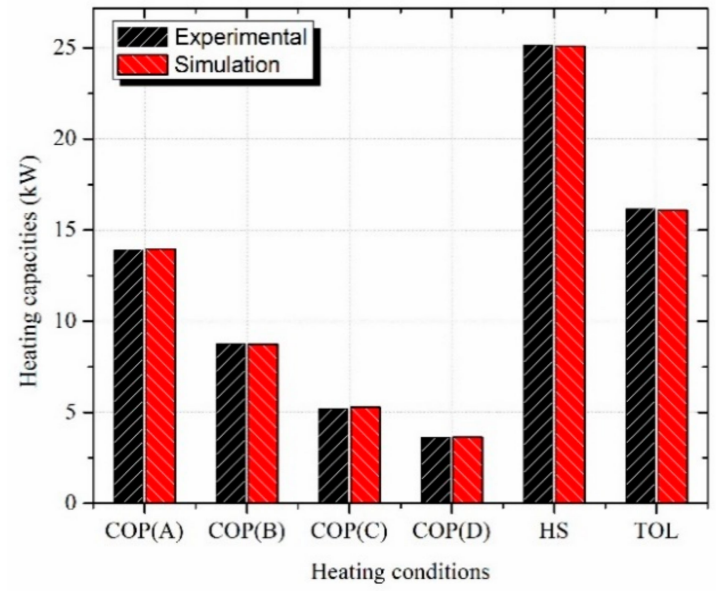

(a)

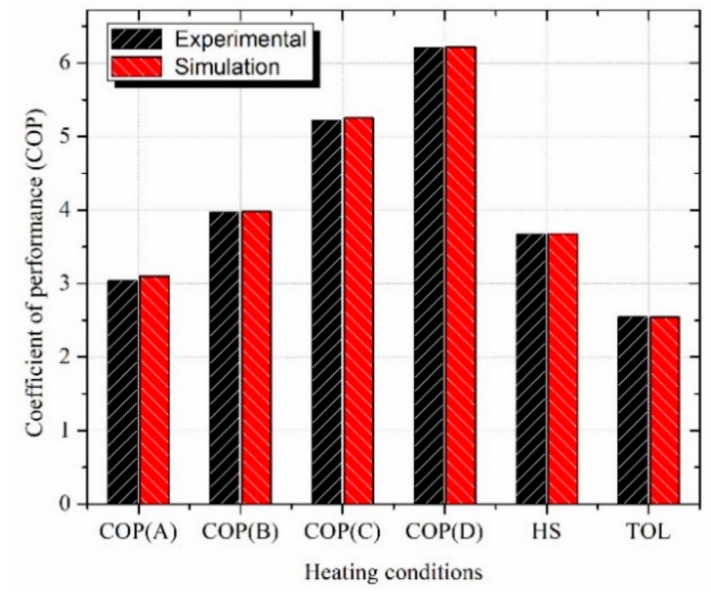

(b)

Figure 8. (a) Comparing heating capacities of heat exchanger; (b) Coefficient of performance (COP) of the cycle.

\section{Results and Discussion}

In this section, numerical results showing the effect of several geometric parameters of finned tube heat exchangers i.e., the number of tube rows, fin pitch, tube length, and different fin configuration on overall heat pump system performance in different seasonal conditions are presented along with discussion. Heat pump cycle performance is evaluated numerically and presented in terms of EER and $\mathrm{COP}$ for cooling and heating conditions respectively.

\subsection{Effect of the Number of Tube Rows}

Figure 9 illustrates the effect of the number of tube rows on system performance. The number of tube rows was varied from 2-10 keeping the rest of the geometrical parameters constant. Around $10 \%$ increase in EER is observed in EER(A) case, while 3.70\% for EER(B) case, as the number of tube rows is increased up to the fourth row. In general, heat transfer and pressure drop are directly proportional to the number of tube rows. These results are in line with the findings of Pongsoi et al. [7] who reported 
an increase in average heat transfer and pressure drop with the increasing number of tube rows. In fact, the rate of increase in pressure loss is more prominent as the number of tube rows increases. This nullifies the positive aspect of heat transfer improvement. Hence no further increase in EER is observed at a higher number of tube rows. In EER(C) case, a slight increase of $0.4 \%$ in EER is observed initially from second to third depth row and becomes almost constant afterward. In EER(D) case, no increase in EER is observed for all number of tube rows. This insensitive behavior of EER for EER(C) and EER(D) cases is ascribed to low face velocities of the outdoor conditions EER(C) and EER(D). As the face velocity decreases, the heat transfer rate of the next coming number of tube rows becomes less effective.

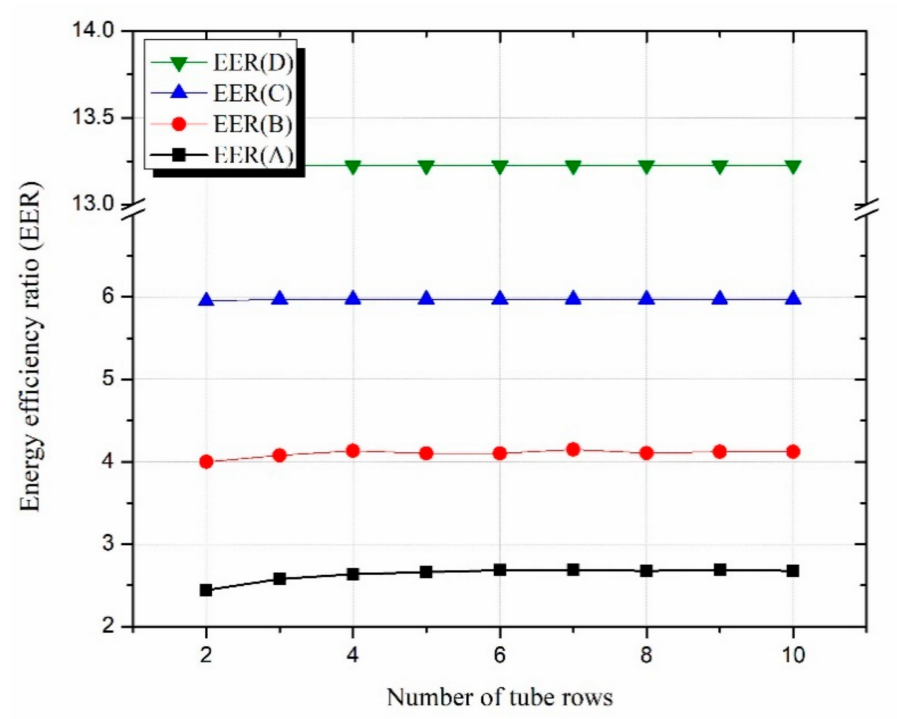

Figure 9. Effect of the number of tube rows on energy efficiency ratio (EER).

Figure 10 shows four curves for COPs at various number of tube rows in different heating conditions. All these curves indicate small improvement in performance initially for the first few rows and fluctuate around it later for a higher number of tube rows. The maximum percentage increase found for all heating conditions varies between $2.85-5.65 \%$. The slight fluctuation in the results is attributed to the convergence criteria of the simulation model. Additionally, the heat transfer rate in the vicinity of the first three rows is higher as compared to the next rows, as a result of which increase in $\mathrm{COP}$ from second to third row is more prominent than the proceeding rows. The unaffected behavior of COP at a higher number of tube rows is due to high-pressure drop with small improvement in heat transfer rate. A similar type of results regarding the effect of the number of tube rows on finned tube heat exchanger performance with large fins was reported by Kim, Y.H. [6]. His study showed that the Colburn $\mathrm{j}$ factor becomes uniform at higher tube rows.

To assess the seasonal performance variation of the heat pump system under varying number of tube rows of the outdoor heat exchanger, SEER and SCOP are plotted against the number of tube rows in Figure 11. It can be seen from the results that SEER increases up to the fourth tube row while that of SCOP up to the fifth row. The percentage increase for the former is $3.21 \%$, while that of the latter is $5.32 \%$, respectively. For the initial few tube rows, a small increase in heat transfer is accompanied by a small increase in pressure drop and for tube rows greater than 4 , a slight increase in heat transfer is accompanied by a large increase in pressure drop. It shows that the amount of pressure drop increases drastically with the increasing number of tube rows which raises the required input power. Hence, overall performance improvement is minimized. This observation is similar to the experimental study of Rich et al. [4] but the present results show finer details as to how the seasonal performance is affected by the increasing number of tube rows of a heat exchanger. 


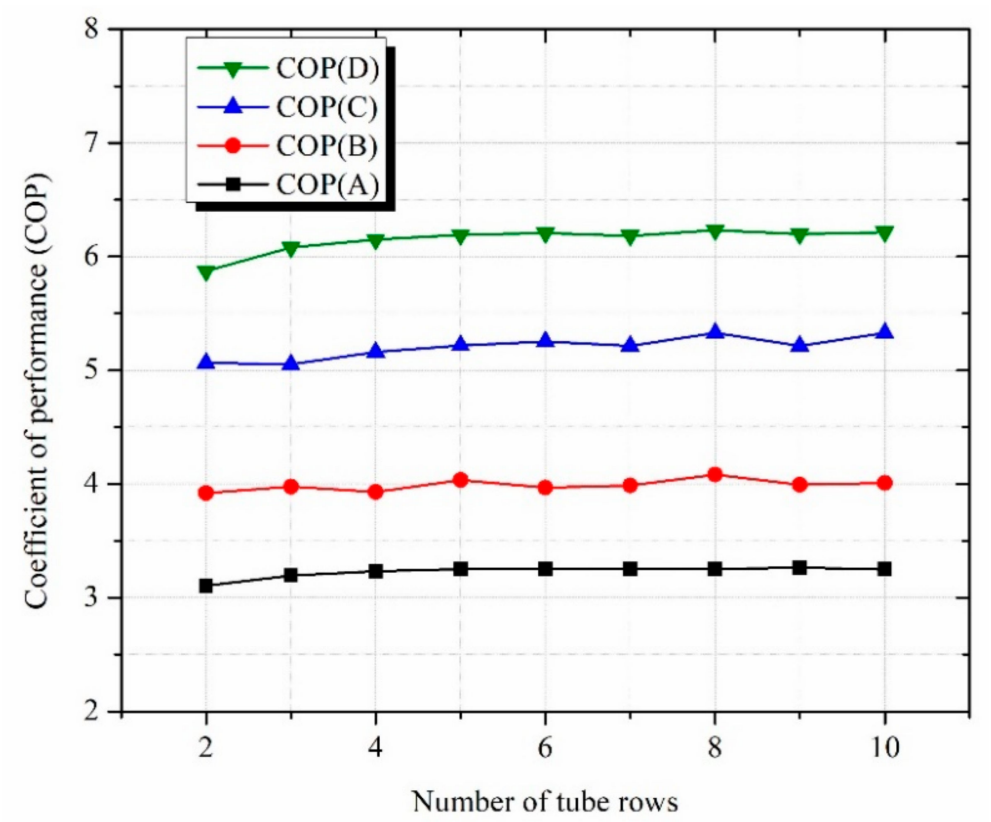

Figure 10. Effect of the number of tube rows on the coefficient of performance (COP).

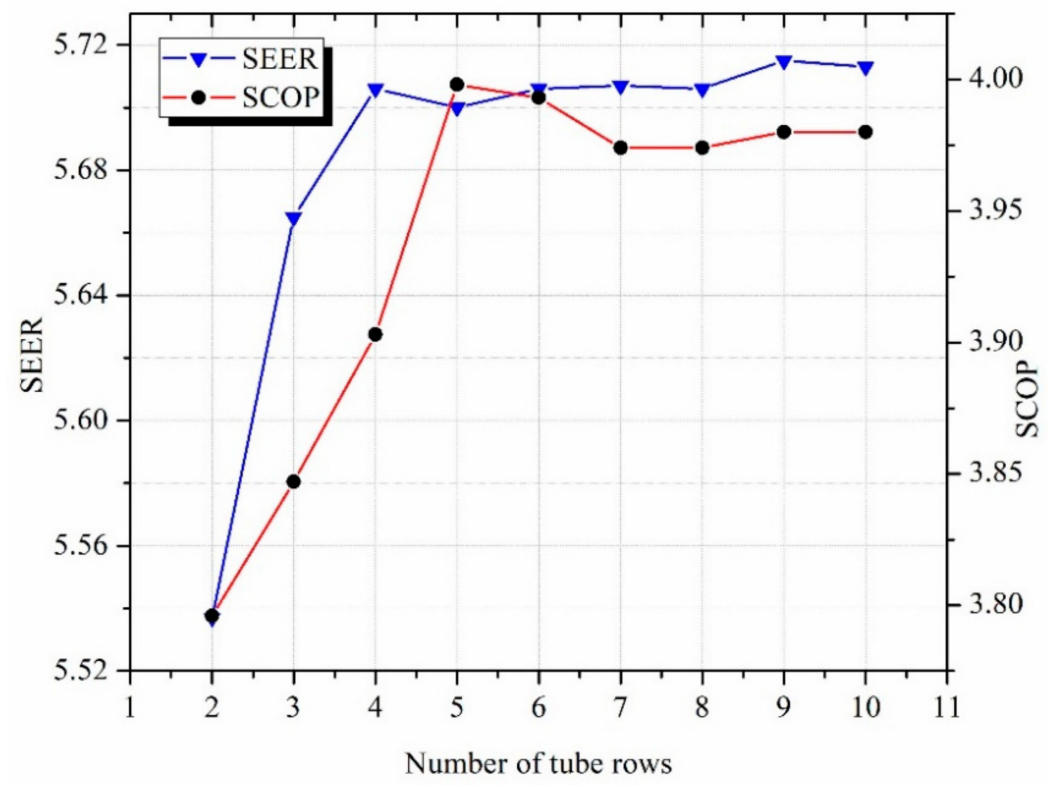

Figure 11. Effect of the number of tube rows on seasonal energy efficiency ratio (SEER) and seasonal coefficient of performance (SCOP).

\subsection{Effect of Fin Pitch}

A wide range of fin pitch varying from 1.2-2.5 mm was selected to investigate its effect on heat pump performance. As shown in Figure 12, a slight decrease of 3.94\% and 2.40\% in EER is observed in EER(A) and EER(B) cases, respectively as the fin pitch is increased. This is because higher fin pitch leads to fewer fins that reduce available heat transfer surface area and pressure drop. However, at high Reynolds number, Colburn $\mathrm{j}$ factor decrement is more prominent as compared to friction factor $f$ which leads to the reduction in system EER [36]. A similar trend was reported for wavy [13] and L-footed spiral [14] fin and tube heat exchangers. Compared to the first two cases, the heat transfer enhancement in $\operatorname{EER}(C)$ and EER(D) is limited by the constraint airflow velocities, hence, fin pitch has no influential effect on system EER in these two conditions. The results also suggest that the efficiency of the system 
is primarily associated with outdoor air velocity rather than fin pitch, as suggested by [26]. That is why no significant effect of fin pitch has been reported for herringbone wavy [5], slit [9], plate [17] and crimped spiral [18] fin and tube heat exchangers.

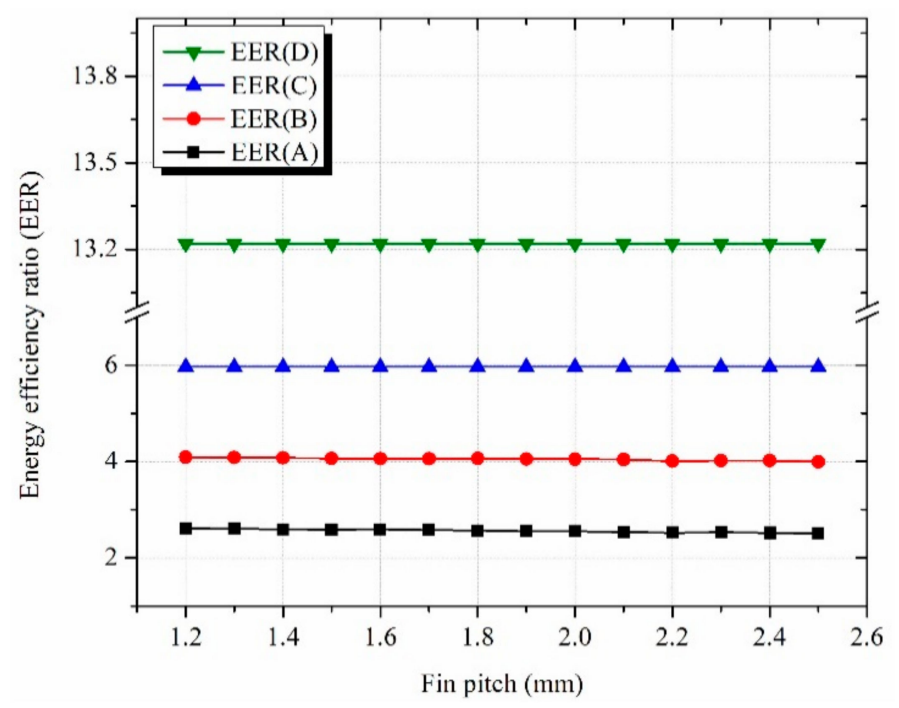

Figure 12. Effect of fin pitch on energy efficiency ratio (EER) in cooling conditions.

By selecting a greater range of fin pitch in heating conditions and performing system analysis, the saw-tooth behavior is observed as shown in Figure 13. In case of COP(A) for fin pitch 1.2-1.4 mm, in case of $\mathrm{COP}(\mathrm{B})$ for fin pitch 1.2-1.5 mm, in case of $\mathrm{COP}(\mathrm{C})$ for fin pitch 1.2-1.7 mm and in case of COP(D) for fin pitch 1.2-1.7 mm a slight decrease in COP is observed which is in line with results of [13] and [14]. After that point, a certain increase in COP is observed in all cases due to the increase in heat exchanger capacity with almost the same input power. This may be due to the better mixing of air as fin pitch increases. Further increase in fin pitch disturbs the airflow mixing and an initial behavior is repeated. These results are in line with the findings of Liu [19] who reported an increase in heat transfer performance with increasing fin pitch initially up to $2.54 \mathrm{~mm}$ and then suddenly decreases beyond that point up to $3.15 \mathrm{~mm}$. Maximum difference observed in $\mathrm{COP}(\mathrm{A})$ is $15.77 \%, \mathrm{COP}(\mathrm{B})$ is $8.24 \%$, $\mathrm{COP}(\mathrm{C})$ is $5.54 \%$ and $\mathrm{COP}(\mathrm{D})$ is $3.82 \%$.

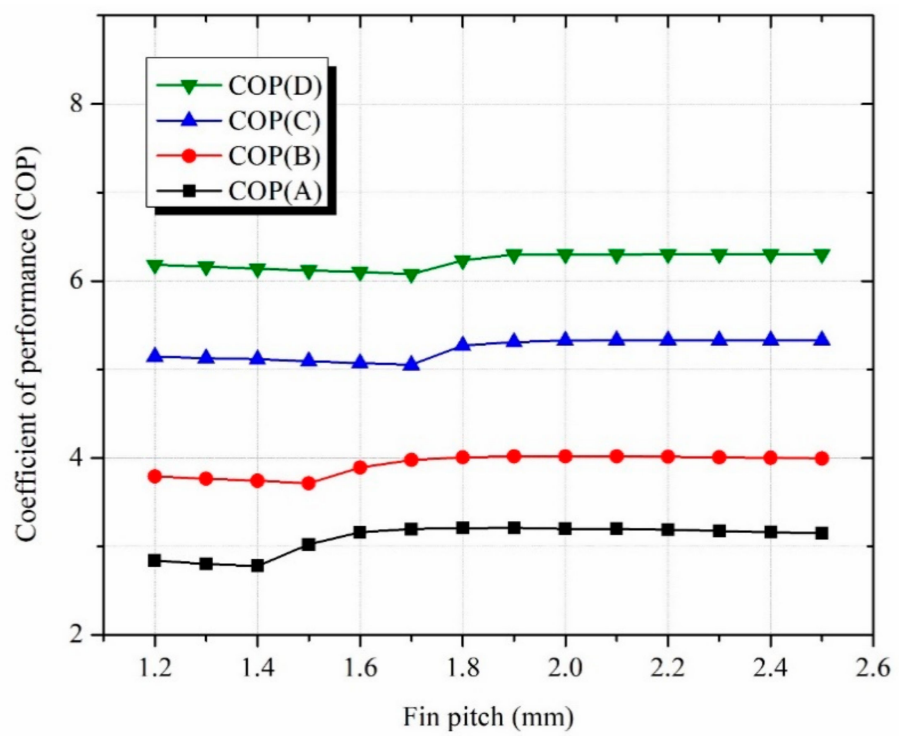

Figure 13. Effect of fin pitch on the coefficient of performance (COP) in heating conditions. 
Figure 14 shows the behavior of SEER and SCOP at various fin pitches. The optimum fin pitch can be selected by observing the graphs. Maximum values are observed at fin pitch $1.6 \mathrm{~mm}$ and $1.7 \mathrm{~mm}$.

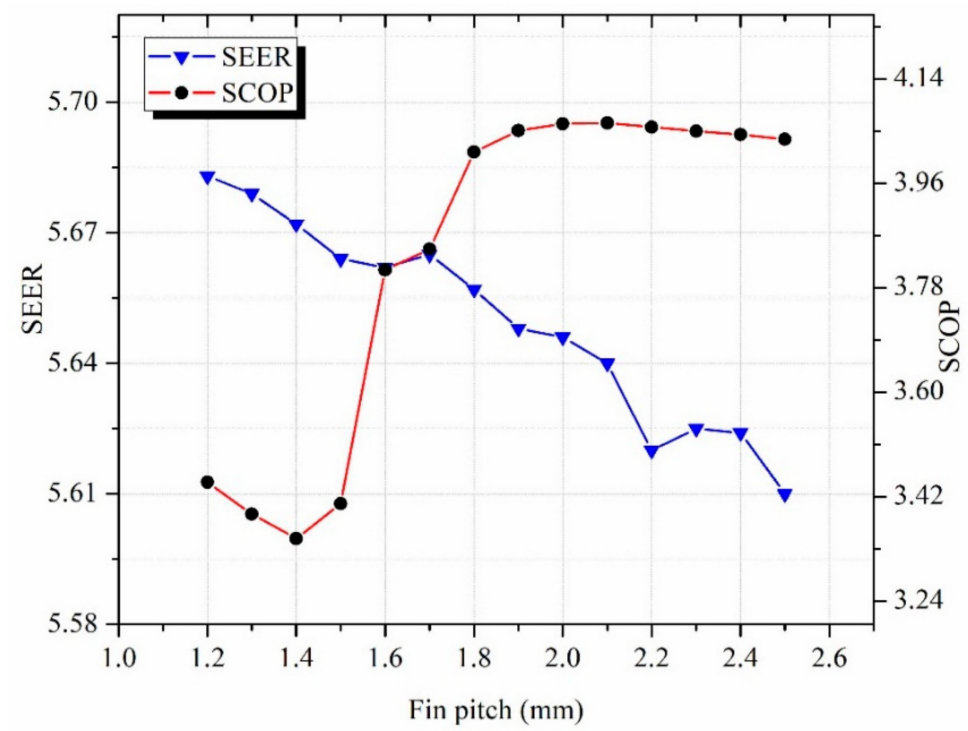

Figure 14. Effect of fin pitch on seasonal energy efficiency ratio (SEER) and seasonal coefficient of performance (SCOP).

\subsection{Effect of Tube Length}

A wide range of tube lengths from $800-2800 \mathrm{~mm}$ is selected to investigate the effect of tube length on heat pump performance. Some of the parameters like tube pitch, fin pitch, and number of fins are interdependent on tube length but are supposed constant for the current study. Heat transfer and pressure drop are directly proportional to the length of the tube. As the length of the tube increases, more surface area is available to transfer heat compromising high-pressure drop [37]. Therefore, to predict the overall effect of tube length on the heat pump cycle, curves are plotted for EER and COP at various tube lengths as shown in Figure 15a,b and Figure 16. In cooling conditions, $12.43 \%$ increment in performance is observed by changing tube length for the first case-i.e., EER(A) $-8.87 \%$ for the second case-i.e., EER(B) — but no real improvement $(<1 \%)$ is observed for third and fourth cases. Comparing the slope of the curve at various lengths in EER(A) and EER(B), it is observed that the rate of heat transfer performance improvement reduces as the length of the tube increases. It is due to the fact that as the heat continued to transfer along the length of the tube, the temperature difference between the working fluids reduces and as a result less heat is transferred with higher pressure drop. Similar observation has been reported by Ali [22] for shell and tube heat exchangers but the present results provide much finer details regarding the effect of tube length under different seasonal conditions. In the case of EER(C) and EER(D) as shown in Figure 15b where outdoor working conditions are not severe-i.e., low temperatures and air velocities-the required cooling demand can be achieved with smaller tubes. Hence further increase in tube length in such cases will be ineffective.

Figure 16 shows the behavior of the heat pump COP as the tube length is varied from $800-2800 \mathrm{~mm}$. As the length of the tube is directly proportional to both heat transfer and pressure drop, both increases with an increase in length. Up to a certain increase in tube length, heat transfer enhancement is more effective as compared to pressure drop, hence improved overall system COP but the deterioration in performance starts as soon as the increase in pressure drop overcomes heat transfer enhancement. A maximum increment of $9.50 \%$ is found in $\mathrm{COP}(\mathrm{A}), 4.37 \%$ in $\mathrm{COP}(\mathrm{B}), 4.46 \%$ in $\mathrm{COP}(\mathrm{C})$, and $6.20 \%$ in $\mathrm{COP}(\mathrm{D})$. The concave downward curve for case $\mathrm{COP}(\mathrm{A})$ indicates the behavior of the heat pump system in varying tube length. The inflection point is observed at $1600 \mathrm{~mm}$ for case COP(A) which is the optimum length for this condition. Up to this inflection point, the heat transfer rate dominates pressure losses, therefore $\mathrm{COP}$ of the system increases. The opposite is true for tube lengths greater 
than $1600 \mathrm{~mm}$. For cases i.e., $\mathrm{COP}(\mathrm{B}), \mathrm{COP}(\mathrm{C})$, and $\mathrm{COP}(\mathrm{D})$ concave downward curves repeating in a sinusoidal way are generated with a left shift in the initial maximum and minimum points due to reduction in outdoor face velocities and required heating demands.

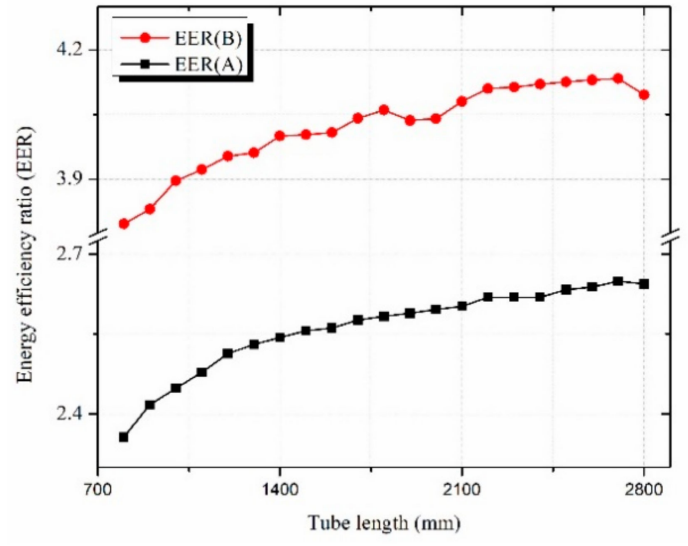

(a)

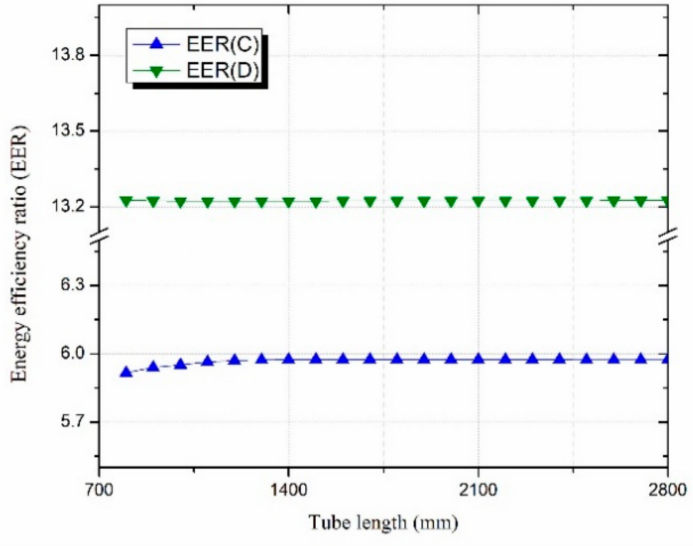

(b)

Figure 15. Effect of tube length on energy efficiency ratio (EER) in cooling conditions (a) EER(A) and $\operatorname{EER}(\mathrm{B}) ;(\mathbf{b}) \operatorname{EER}(\mathrm{C})$ and $\operatorname{EER}(\mathrm{D})$.

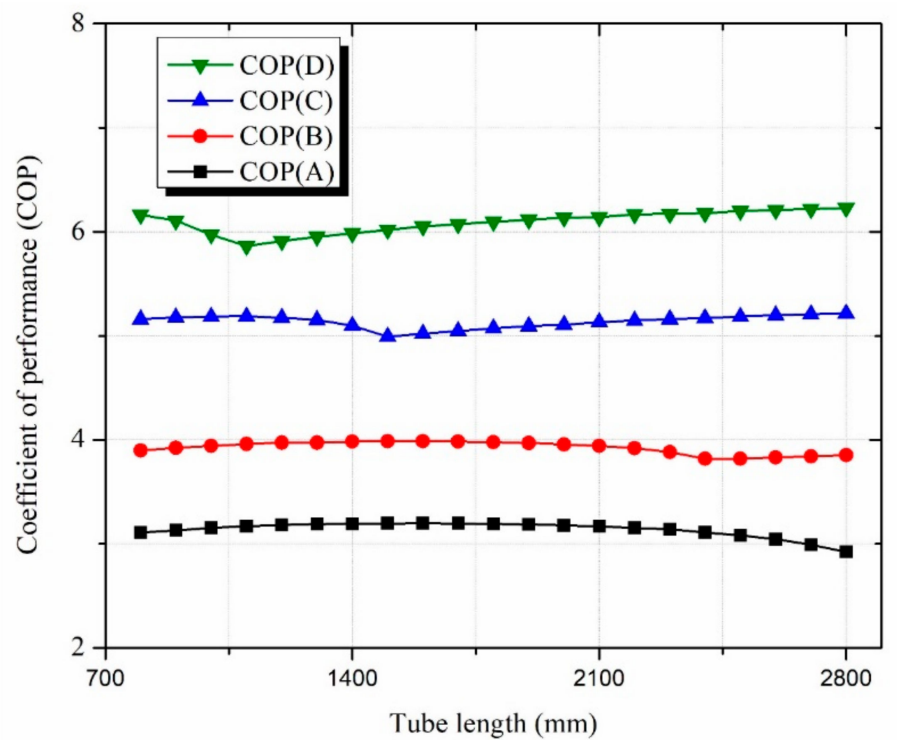

Figure 16. Effect of tube length on the coefficient of performance (COP) in heating conditions.

To a better understanding of tube length effect on system performance, the rest of the parameters are kept constant. SEER and SCOP computed against the length of the tube are shown in Figure 17. As noted in the individual seasonal performance variation, annual heat pump performance in summer also shows increment in SEER with increasing tube length. The value of SEER increases by $3.55 \%$ as the tube length is increased from $800 \mathrm{~mm}$ to $1800 \mathrm{~mm}$; whereas, it increases only $0.67 \%$ as the tube length is increased from $1800-2800 \mathrm{~mm}$. This indicates a reduction in heat exchanger effectiveness as the tube length increases due to the low-temperature difference between heat transfer fluids. On the other hand, a slight increase in SCOP is found as the tube length is increased up to $1200 \mathrm{~mm}$ and decreases beyond that with a maximum percentage difference of $4.32 \%$. Based on a similar kind of observation, Baglivo et al. [38] suggested splitting a $50 \mathrm{~m}$ probe into two parts to make it more effective in an air-cooled heat pump coupled with HAGHE. 


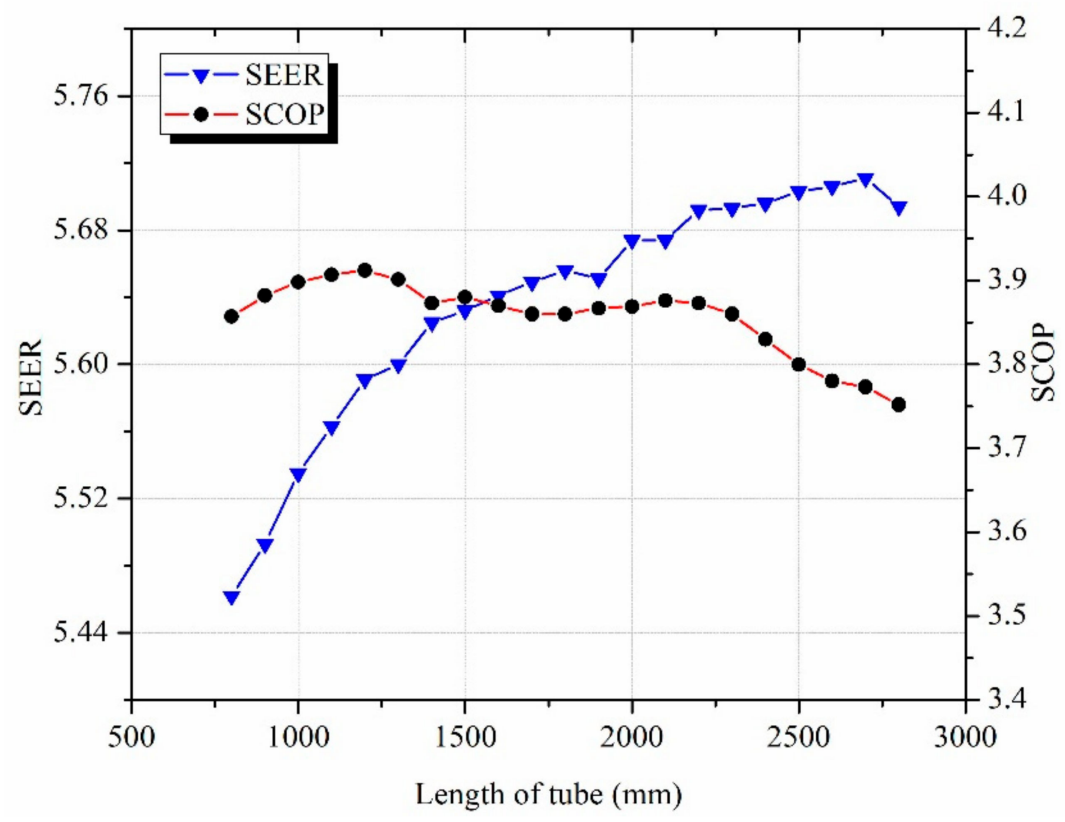

Figure 17. Effect of tube length on seasonal energy efficiency ratio (SEER) and seasonal coefficient of performance (SCOP).

\subsection{Effect of Fin Configuration}

Performance analysis of the heat pump system is carried out under several fin configurations. Plate, louvered, slit, and $\mathrm{H}$ fins are commonly used fins having the ability to improve air-side heat transfer at a cost of an increase in pressure drop. The simultaneous increase in heat transfer and pressure drop on overall heat pump performance can be recognized by comparing EER for different fin configurations. The inspection of Figure 18 shows higher EER value for slit fins as compared to plate, louver and $\mathrm{H}$ fins in cases EER(A), EER(B), and EER(C). An increase of 3.79\% has been found for slit fins in condition EER(A) and it reduces as the condition changes from EER(A) to EER(B) and so on, with condition EER(D) having no further improvement. Slit fins have the ability to provide larger volumes for air which reduces heat conduction and facilitates heat convection between the tube rows which enhances heat transfer performance. This observation is in line with the experimental study of Santosa [28] but the present numerical approach provides a much wider range of working conditions and geometric parameters. On the other hand, louver fins have a high heat transfer coefficient accompanied by high-pressure drop. The increment in pressure drop exceeds that of heat transfer which leads to high input power, thus reduces EER [39]. However, the performance of louver fins can be improved by increasing their width [40]. 


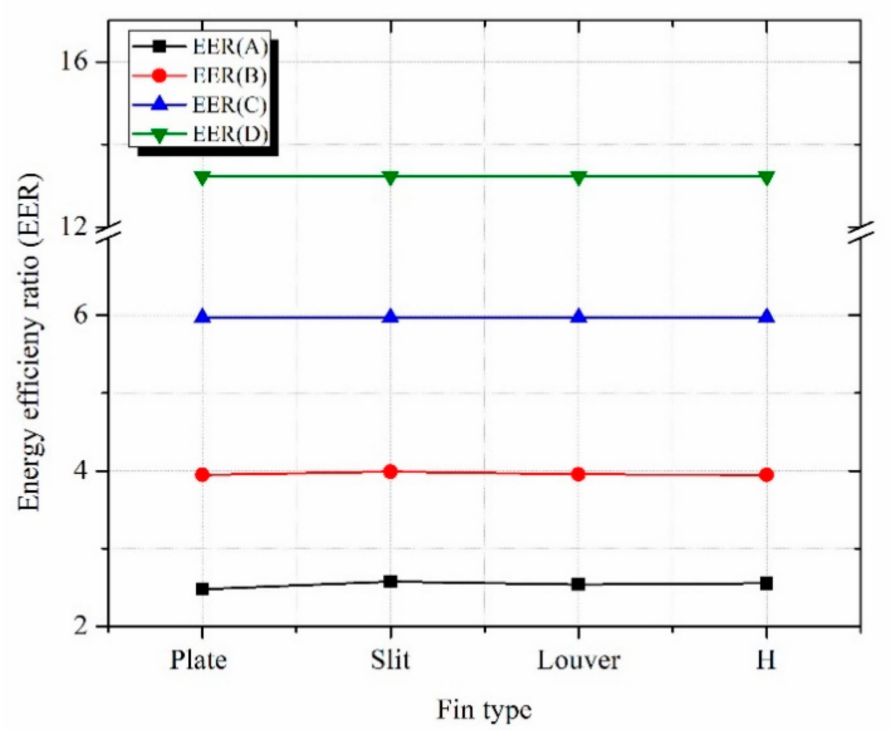

Figure 18. Effect of fin configuration on energy efficiency ratio (EER) in cooling conditions.

Figure 19 shows COP for different fins under heating conditions. Although the percent increase in $\mathrm{COP}$ for slit fins is small but consistent throughout the working conditions. These fins show better heat pump performance than plate, louver, and $\mathrm{H}$ fins in heating as well as cooling mode, due to low heat dissipation. The overall effect of fins on the system performance throughout the year can be predicted from Figure 20 using SEER and SCOP.

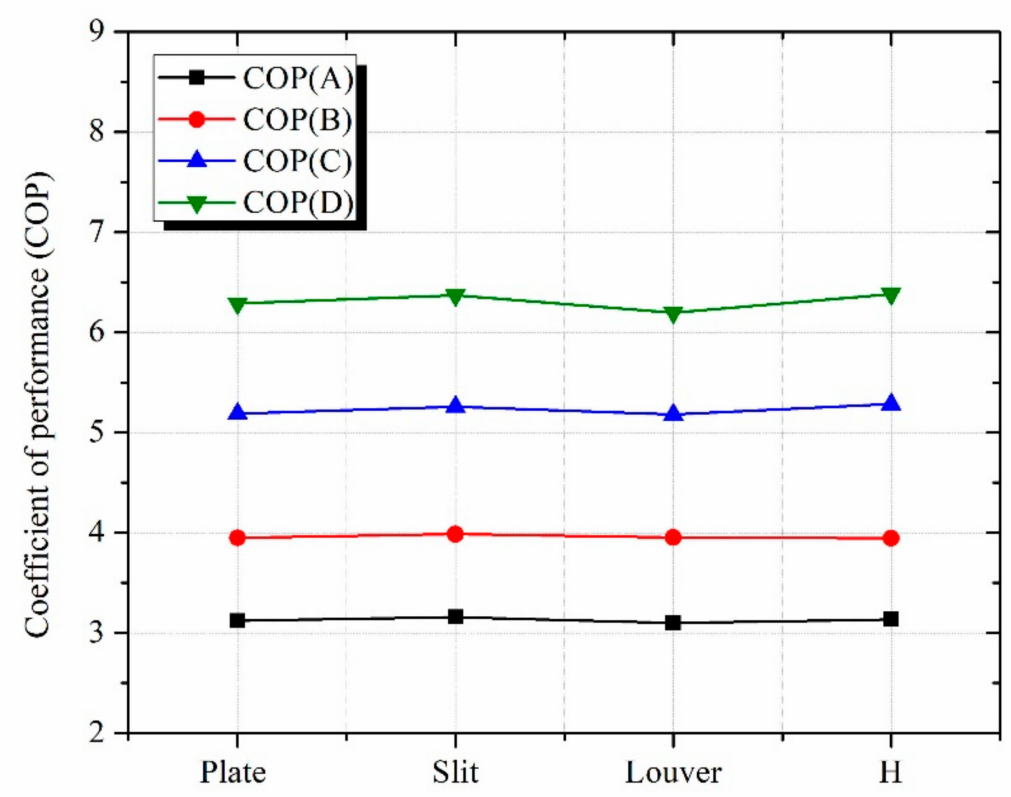

Figure 19. Effect of fin configuration on the coefficient of performance (COP) in heating conditions. 


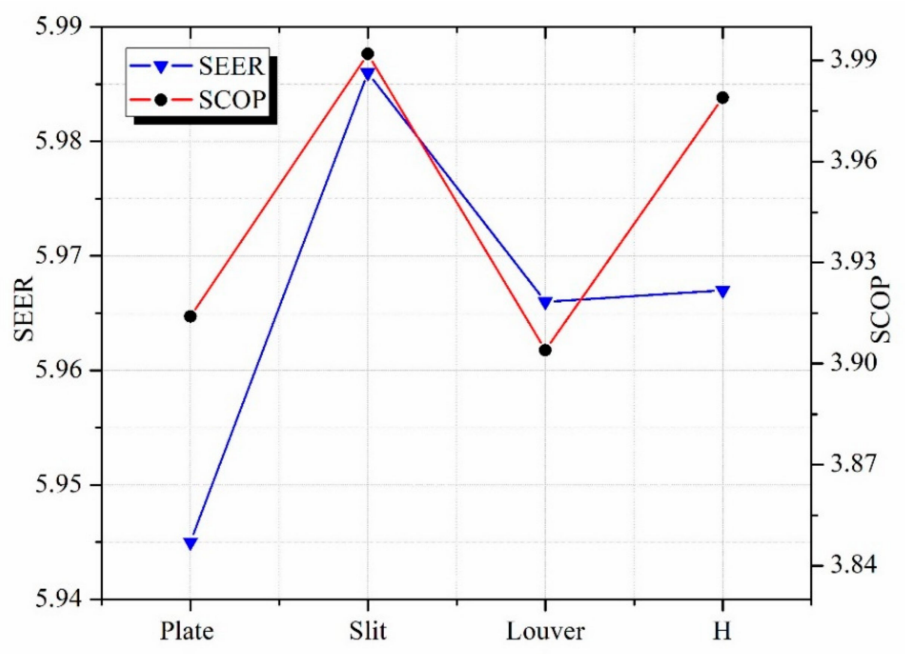

Figure 20. Effect of fin configuration on seasonal energy efficiency ratio (SEER) and seasonal coefficient of performance (SCOP).

\section{Conclusions}

The current study has been carried out to determine an energy-efficient heat pump system by investigating the effect of outdoor unit heat exchanger geometric parameters-i.e., the number of tube rows, fin pitch, tube length, and fin configuration on heat pump system performance. This study is essential in selecting an efficient heat exchanger design based on SEER and SCOP rather than a single peak load design point. The number of tube rows was varied from 2-10, the fin pitch was varied from $1.4-2.5 \mathrm{~mm}$ and the length of the tube was varied from $800-2800 \mathrm{~mm}$. Moreover, four different fin configurations were also analyzed. The findings of the present study have been listed below.

- As the number of tube rows increases, SEER and SCOP increases significantly up to fourth and fifth tube row respectively and are unaffected thereafter. This implies high-pressure drop accompanied by a small heat transfer enhancement as the number of tube rows exceeds the aforementioned rows.

- Maximum performance was observed at fin pitch $1.8 \mathrm{~mm}$. SEER decreases and SCOP increases slightly with increasing fin pitch. This implies the effect of fin pitch is significantly affected by operating conditions.

- Maximum SEER and SCOP were observed at $2600 \mathrm{~mm}$ and $1200 \mathrm{~mm}$ tube length respectively. The improvement was found to be more significant initially as the tube length increases from $800 \mathrm{~mm}$ to $1800 \mathrm{~mm}$, but later on, it decreases as the tube length increases further. The results revealed that optimal tube length should be selected based on seasonal working conditions.

- Maximum heat pump performance was achieved using slit fins as compared to plate, louver, and $\mathrm{H}$ fins.

The current study is limited to a few geometric parameters of the outdoor unit. Further studies will extend the matrix by optimizing all geometric parameters associated with heat exchanger geometry based on partial load operating conditions rather than a single peak load. Designing heat exchangers based on SEER and SCOP can reduce huge energy consumption. A similar idea can also be extended to other types of heat exchangers used in industrial applications.

Author Contributions: S.I. did the simulation analysis and drafted the manuscript. M.-H.K. supervised the research and edited the manuscript. The authors read and approved the manuscript.

Funding: This research received no external funding.

Conflicts of Interest: The authors declare no conflict of interest. 


\section{Nomenclature}

A

$C_{p}$

Elbu

$F_{i}$

$f$

$G_{i}$

$h$

H

$H_{c e}$

j

$k_{t}$

$m$

$P$

$P_{\text {design, }}$

$Q$

R

T

$T_{j}$

$t$

U

Abbreviations

$\mathrm{AC}$

COP

CK

DBT

EER

$\mathrm{H}$

HS

HAGHE

L

OFF

SB

SEER

SCOP

TOL

TO

WBT

Greek symbols

\section{$\phi$}

$\Phi$

\section{Subscript}

a

$c$

fs

$f t$

h

ht

i

j

m

$n$

o

$r$

$t$
Surface area, $\mathrm{m}^{2}$

Specific heat capacity, kJ/kg

Required capacity of an electric backup heater, $\mathrm{kW}$

$\mathrm{m}_{\mathrm{i}} / \mathrm{m}_{\text {total }}$ fraction of total refrigerant mass flow rate flowing through $i$ th circuit Friction factor

Refrigerant mass flux for $i$ th circuitry branch, $\mathrm{kg} / \mathrm{m}^{2} \mathrm{~s}$

Heat transfer coefficient, $\mathrm{W} / \mathrm{m}^{2} \mathrm{~K}$

Number of hours the unit is considered to work in

Equivalent cooling hours

Colburn factor

Thermal conductivity of the tube, $\mathrm{W} / \mathrm{mK}$

Mass flow rate, $\mathrm{kg} / \mathrm{s}$

The electricity consumption or Pressure drop, $\mathrm{kW}$ or $\mathrm{kPa}$

Full load electricity consumption, $\mathrm{kW}$

Heat transfer rate or Reference annual demand, $\mathrm{kW}$ or $\mathrm{kWh}$

Flow resistance offered by a given branch leaving a split or Resistance, $\left(\mathrm{W} / \mathrm{m}^{2}\right.$

$\mathrm{K})^{-1}$

Temperature, ${ }^{\circ} \mathrm{C}$ or $\mathrm{K}$

Corresponding temperature or bin temperature, $\mathrm{K}$

Tube thickness, $\mathrm{m}$

Overall heat transfer coefficient, $\mathrm{W} / \mathrm{m}^{2} \mathrm{~K}$

Air conditioning

Coefficient of performance

Crankcase heater mode

Dry bulb temperature, $\mathrm{K}$

Energy efficiency ratio

Height of compressor, $\mathrm{mm}$

Heating standard

Horizontal air ground heat exchanger

Length of capillary tube, $\mathrm{m}$

OFF mode

Standby mode

Seasonal energy efficiency ratio

Seasonal coefficient of performance

Temperature operating limit, $\mathrm{K}$

Thermostat off mode

Wet bulb temperature, $\mathrm{K}$

Fin efficiency

Diameter, $\mathrm{mm}$

Air side

Cooling

Fin surface

Fin tube contact

Heating

Heat transfer surface

Inner side of the tube, inlet or $i$ th

The bin number

Mean

The amount of bins

Outer side of the tube

Refrigerant side

Tube 


\section{References}

1. Blanco, G.; Gerlagh, R.; Suh, S.; Barrett, J.; de Coninck, H.C.; Morejon, C.D.; Mathur, R.; Nakicenovic, N.; Ahenkorah, A.O.; Pan, J. Drivers, Trends and Mitigation. In Climate Change 2014: Mitigation of Climate Change. IPCC Working Group III Contribution to AR5; Cambridge University Press: Cambridge, UK, 2014; pp. 351-412.

2. Netz, B.; Davidson, O.R.; Bosch, P.R.; Dave, R.; Meyer, L.A. Climate Change 2007: Mitigation. Contribution of Working Group III to the Fourth Assessment Report of the Intergovernmental Panel on Climate Change; Intergovernmental Panel on Climate Change (IPCC): Geneva, Switzerland, 2007.

3. Frass, F. Principles of Finned-Tube Heat Exchanger Design for Enhanced Heat Transfer, 2nd ed.; WSEAS Press: Vienna, Austria, 2015.

4. McQuiston, F.C. Finned Tube Heat Exchangers: State of the Art for the Air Side. In Proceedings of the 5th Annual Heat Pump Technology Conference, Stillwater, OK, USA, 14 April 1980.

5. Wongwises, S.; Chokeman, Y. Effect of fin pitch and number of tube rows on the air side performance of herringbone wavy fin and tube heat exchangers. Energy Convers. Manag. 2005, 46, 2216-2231. [CrossRef]

6. Kim, Y.H.; Kim, Y.C.; Kim, J.R.; Sin, D.S. Effects of Fin and Tube Alignment on the Heat Transfer Performance of Finned-Tube Heat Exchangers with Large Fin Pitch. In Proceedings of the International Refrigeration and Air Conditioning Conference, West Lafayette, IN, USA, 12-15 July 2004.

7. Pongsoi, P.; Pikulkajorn, S.; Wang, C.; Wongwises, S. Effect of number of tube rows on the air-side performance of crimped spiral fin-and-tube heat exchanger with a multipass parallel and counter cross-flow configuration. Int. J. Heat Mass Transf. 2012, 55, 1403-1411. [CrossRef]

8. Tang, L.H.; Min, Z.; Xie, G.N.; Wang, Q.W. Fin Pattern Effects on Air-Side Heat Transfer and Friction Characteristics of Fin-and-Tube Heat Exchangers with Large Number of Large-Diameter Tube Rows. Heat Transf. Eng. 2009, 30, 171-180. [CrossRef]

9. Wang, C.; Lee, W.; Sheu, W.; Chang, Y. Parametric study of the air-side performance of slit fin-and-tube heat exchangers in wet conditions. Proc. Inst. Mech. Eng. Part C J. Mech. Eng. Sci. 2015, 215, 1111-1121. [CrossRef]

10. Erdem, S. The effects of fin-and-tube evaporator geometry on heat pump performance under dehumidifying conditions. Int. J. Refrig. 2015, 57, 35-45. [CrossRef]

11. Elmahdy, A.H.; Biggs, R.C. Finned tube heat exchanger: Correlation of dry surface heat transfer data. ASHRAE Trans. 1979, 85, 262-273.

12. Jang, J.Y.; Wu, M.C.; Chang, W.J. Numerical and experimental studies of three- dimensional plate-fin and tube heat exchangers. Int. J. Heat Mass Transf. 1996, 39, 3057-3066. [CrossRef]

13. Jang, J.Y.; Chen, L.K. Numerical analysis of heat transfer and fluid flow in a three-dimensional wavy-fin and tube heat exchanger. Inf. J. Hear Mass Transf. 1997, 40, 3981-3990. [CrossRef]

14. Pongsoi, P.; Promoppatum, P.; Pikulkajorn, S.; Wongwises, S. Effect of fin pitches on the air-side performance of L-footed spiral fin-and-tube heat exchangers. Int. J. Heat Mass Transf. 2013, 59, 75-82. [CrossRef]

15. Wang, C.C. Recent progress on the air-side performance of fin-and-tube heat exchangers. Int. J. Heat Exch. 2000, 1, 49-76.

16. Chen, H.; Hsu, W. Estimation of heat transfer coefficient on the fin of annular-finned tube heat exchangers in natural convection for various fin spacings. Int. J. Heat Mass Transf. 2007, 50, 1750-1761. [CrossRef]

17. Wang, C.C.; Chang, Y.J.; Hsieh, Y.C.; Lin, Y.T. Sensible heat and friction characteristics of plate fin-and-tube heat exchangers having plane fins. Int. J. Refrig. 1996, 19, 223-230. [CrossRef]

18. Pongsoi, P.; Pikulkajorn, S.; Wongwises, S. Effect of fin pitches on the optimum heat transfer performance of crimped spiral fin-and-tube heat exchangers. Int. J. Heat Mass Transf. 2012, 55, 6555-6566. [CrossRef]

19. Liu, Y.; Wongwises, S.; Chang, W.; Wang, C. Airside performance of fin-and-tube heat exchangers in dehumidifying conditions-Data with larger diameter. Int. J. Heat Mass Transf. 2010, 53, 1603-1608. [CrossRef]

20. Onan, C.; Erdem, S.; Özkan, D.B.; Heperkan, H.A. The Effects of Fin Spacing and Tube Outer Diameter of Evaporator on System Performance in Heat Pump Tumble Dryers. In Proceedings of the International Refrigeration and Air Conditioning Conference, West Lafayette, IN, USA, 14-17 July 2014.

21. Ameel, B.; Degroote, J.; T'Joen, C.; Huisseune, H.; De Schampheleire, S.; Vierendeels, J.; De Paepe, M. Accounting for the effect of the heat exchanger length in the performance evaluation of compact fi $\mathrm{n}$ and tube heat exchangers. Appl. Therm. Eng. 2014, 65, 544-553. [CrossRef] 
22. Abd, A.A.; Kareem, M.Q.; Naji, S.Z. Performance Analysis of Shell and Tube Heat Exchanger: Parametric Study. Case Stud. Therm. Eng. 2018, 12, 563-568. [CrossRef]

23. Javaherdeh, K.; Vaisi, A.; Moosavi, R. The effects of fin height, fin-tube contact thickness and louver length on the performance of a compact fin-and-tube heat exchanger. Int. J. Heat Technol. 2018, 36, 825-834. [CrossRef]

24. Bhuiyan, A.A.; Islam, A.K.M.S. Thermal and hydraulic performance of finned-tube heat exchangers under different flow ranges: A review on modeling and experiment. Int. J. Heat Mass Transf. 2016, 101, 38-59. [CrossRef]

25. Wen, M.; Ho, C. Heat-transfer enhancement in fin-and-tube heat exchanger with improved fin design. Appl. Therm. Eng. 2009, 29, 1050-1057. [CrossRef]

26. Chen, H.; Wang, Y.; Zhao, Q.; Ma, H.; Li, Y.; Chen, Z. Experimental Investigation of Heat Transfer and Pressure Drop Characteristics of H-type Finned Tube Banks. Energies 2014, 7, 7094-7104. [CrossRef]

27. Santosa, I.M.C.; Gowreesunker, B.L.; Tassou, S.A.; Tsamos, K.M.; Ge, Y. Investigations into air and refrigerant side heat transfer coefficients of finned-tube $\mathrm{CO}_{2}$ gas coolers. Int. J. Heat Mass Transf. 2017, 107, 168-180. [CrossRef]

28. Micheli, L.; Reddy, K.S.; Mallick, T.K. Experimental comparison of micro-scaled plate-fins and pin-fins under natural convection. Int. Commun. Heat Mass Transf. 2016, 75, 59-66. [CrossRef]

29. ANSYS FLUENT. FLUENT user's guide release 16.0 2015.; ANSYS: Canonsburg, PS, USA, 2015.

30. Lin, A.; Sun, Y.; Zhang, H.; Lin, X.; Yang, L.; Zheng, Q. Fluctuating characteristics of air-mist mixture flow with conjugate wall-film motion in a compressor of gas turbine. Appl. Therm. Eng. 2018, 142, 779-792. [CrossRef]

31. An, C.S.; Kim, M.H. Thermo-hydraulic analysis of multi-row cross-flow heat exchangers. Int. J. Heat Mass Transf. 2018, 120, 534-539. [CrossRef]

32. Kim, K.J. Private Communication of Samsung Electronics Co. Ltd.; Samsung Electronics Co. Ltd: Suwon, Korea, 2018.

33. Kim, M.H. A study on the performance of a split system inverter air-conditioner at different operation conditions. Trans. Korean Soc. Mech. Eng. B 1998, 22, 113-121.

34. Domanski, P.A. EVSIM-An Evaporator Simulation Model Accounting for Refrigerant and One Dimensional Air Distribution; No. NIST Interagency/Internal Report (NISTIR)-89-4133; US Department of Commerce, National Institute of Standards and Technology: Gaithersburg, MD, USA, 1989.

35. Traviss, D.P.; Baron, A.B.; Rohsenow, W.M. Forced-Convection Condensation Inside Tubes; Technical Report No. 74; M.I.T. Heat Transfer Laboratory: Cambridge, MA, USA, 1971.

36. Saleem, A.; Kim, M.H. CFD analysis on the air-side thermal-hydraulic performance of multi-louvered fin heat exchangers at low Reynolds numbers. Energies 2017, 10, 823. [CrossRef]

37. Ravi, R.; Pachamuthu, S. Design and Development of Innovative Protracted-Finned Counter Flow Heat Exchanger (PFCHE) for an Engine WHR and Its Impact on Exhaust Emissions. Energies 2018, 11, 2717. [CrossRef]

38. Baglivo, C.; Bonuso, S.; Congedo, P.M. Performance Analysis of Air Cooled Heat Pump Coupled with Horizontal Air Ground Heat Exchanger in the Mediterranean Climate. Energies 2018, 11, 2704. [CrossRef]

39. Sadeghianjahromi, A.; Kheradmand, S.; Nemati, H.; Liaw, J.S.; Wang, C.C. Compound heat transfer enhancement of wavy fin-and-tube heat exchangers through boundary layer restarting and swirled flow. Energies 2018, 11, 1959. [CrossRef]

40. Park, M.H.; Kim, S.C. Heating Performance Enhancement of High Capacity PTC Heater with Modified Louver Fin for Electric Vehicles. Energies 2019, 12, 2900. [CrossRef]

(C) 2019 by the authors. Licensee MDPI, Basel, Switzerland. This article is an open access article distributed under the terms and conditions of the Creative Commons Attribution (CC BY) license (http://creativecommons.org/licenses/by/4.0/). 